Session No. 2247

\title{
Strategies for creating accurate updates of CPM construction schedules.
}

\author{
Todd Dunn, P.E. \\ Associate Professor, Rochester Institute of Technology \\ Civil Engineering Technology
}

\begin{abstract}
:
The paper describes practical approaches that students and practitioners can use to accurately update CPM construction schedules. It describes the importance of updates, and also explores common errors made during updates, and methods for correcting them. Its purpose is to provide students and professionals involved in CPM construction scheduling the tools to create reliable and accurate schedule updates using popular application software (Primavera Systems Inc.). Detailed 'means and methods' employed when updating schedules are described. In particular, the paper describes the software settings and approaches for configuring the settings in an effort to achieve accurate, reliable schedule updates.

Introduction:

Creating CPM (Critical Path Method) schedules for construction projects is commonplace. Construction schedules include a group of activities which must be performed in order to complete, say, a new building. Every activity in a construction schedule has an estimated time duration to complete the activity. Examples of activities might include, 'Erect Structural Steel' (with, for example, a ten day duration) or 'Install brick veneer on south wall." Critical path schedules are so-named because these time schedules highlight a subgroup of activities that lie on the critical path. The activities that lie on the critical path are important because a delay in completing any of these activities will result in a delay in completion of the project.
\end{abstract}

Schedulers and/or construction project managers should update their CPM schedules on a regular basis in an effort to compare actual progress on the job with planned progress. Owners will want to know if the project is on schedule, and the only way to provide a quantitative answer to that question is to examine each activity in the schedule and record any progress that has occurred on that activity since the last update. Once the progress is accurately recorded, the application software used to create the schedule can perform calculations that will estimate start and end dates for the remaining (incomplete) activities in the schedule. This may result in a project completion date that has changed since the last update.

Often, however, schedules are not updated regularly, in part because producing accurate updates to an on-going project is not a trivial endeavor. (Another reason regular schedule updates are sometimes ignored is that often owners and contractors loose enthusiasm and motivation for producing the updates. Part of this lethargy is due to their experience with flawed updates). In addition, the popularization of easy-to-use scheduling software has "democratized CPM schedule writing....but it has also put scheduling in the hands of many inexperienced and poorly trained 
practitioners."2. The paper outlines, in detail, several straightforward approaches that can be employed to achieve accurate updates to CPM construction schedules.

1) The importance of accurate updates.

Students in civil engineering technology programs often gain practice in developing CPM construction schedules. They are exposed to the essentials of creating activities, estimating activity durations, and establishing the relationships among activities in the network.

Relationships between activities define the logic connection between them. For example, an activity named "Form foundation walls" could not begin until "Pour footing concrete" is completed. When students finish, they're usually successful in creating a complete CPM schedule that features a reasonable critical path through the network.

In practice, CPM schedules are of limited value to owners/clients unless the schedules are periodically updated. The initial CPM schedule is not enough to satisfy most savvy owners/clients. They recognize that no project ever proceeds exactly as planned and, as such, will demand that the schedule be updated periodically as construction proceeds. They demand regular, accurate updates from their contractor or construction manager in an effort to assess the likelihood of a delayed completion, forecast cash outlays to the contractor, and to better coordinate the relocation of their staff and equipment to the new facility.

Many textbooks dealing with construction project management in general, and scheduling in particular, devote ample space to the development of CPM schedules. Much less, if any, space is devoted to the procedures involved in updating (or statusing) the schedule. This paper examines strategies that can be used in the classroom to give students exposure to and practice in producing accurate updates to CPM schedules.

2) Understanding the 'data date':

Students and practitioners need to recognize the difference between the data date and the project start date. The start date is intuitive; it's the launching date for the project as a whole. When updating a CPM schedule, it's crucial for students to understand the difference between the two dates. The data date can be loosely explained as today's date, or, more accurately, the date that someone (the student, the job's superintendent, the project manager, etc.) visited the job site and evaluated the actual progress of individual activities in the CPM schedule. The data date is sometimes referred to as today's date, but strictly speaking, this is incorrect. For example, the superintendent might have evaluated activities' progress on a Friday, while the student scheduler might not input the changes into his/her software program until the following Monday. Regardless of the day the software is accessed, the data date remains Friday, the day of the on-site evaluation.

3) Evaluating progress on individual activities in the CPM schedule:

Once the data date has been established, the student needs to carefully examine the CPM schedule in detail. He/she needs to critically appraise every activity in the schedule that either a) experienced progress of any kind during the time period since the last update or b) was slated to have progress during the same time period. Students are often careless in this step, 
and it's crucial to convey to them the importance of taking the time to review every activity in the schedule that could have been affected during the time interval since the last update. This is especially important, since some of the available software applications allow the user the option to automatically "update each activity as though it progressed according to its early dates." Actual progress rarely matches planned progress for a group of activities. As such, students should be very wary about using this quick approach for statusing their activities.

The scheduler can review \%complete and/or remaining duration for activities when updating a CPM schedule. Most scheduling software applications employ a formula similar to the following one when evaluation progress on an activity:

$$
\mathrm{D}_{\mathrm{R}}=\mathrm{D}_{\mathrm{O}}(1-\mathrm{P})
$$

where: $\quad D_{R}=$ remaining duration (usually expressed in days) for the activity

$\mathrm{D}_{\mathrm{O}}=$ original estimated duration for the activity

$\mathrm{P}=$ percent complete for the activity, expressed as a decimal.

Use of this formula allows the scheduler to input the percent complete for an activity $(\mathrm{P})$, and have the remaining duration $\left(D_{R}\right)$ automatically calculated. Conversely, the remaining duration $\left(\mathrm{D}_{\mathrm{R}}\right)$ can be input to produce the estimated percent complete $(\mathrm{P})$. For example, suppose that when the schedule was originally developed, before construction began, the student estimated a 10 day duration for an activity called "Form Footings." Thus, $\mathrm{D}_{\mathrm{O}}=10$. Let's assume now that some time has passed, the project is underway, and the student is performing a schedule update. The superintendent tells the student that the "form footings" operation is, say, $40 \%$ complete as of the data date. Therefore, $\mathrm{P}=0.4$. To calculate remaining duration, $\mathrm{D}_{\mathrm{R}}$, we use:

$$
\begin{gathered}
\mathrm{D}_{\mathrm{R}}=\mathrm{D}_{\mathrm{O}}(1-\mathrm{P}) \\
\mathrm{D}_{\mathrm{R}}=10(1-0.4) \\
\mathrm{D}_{\mathrm{R}}=6 \text { days. }
\end{gathered}
$$

"Form footings" apparently needs an additional 6 days from the data date to complete. This 6 day value for $D_{R}$ is automatically folded into the schedule calculations by the application software. Forecasted start and finish dates for activities that are downstream ("successors") to "Form Footings" are automatically calculated by the software, based on the assumption that 6 days are needed (from the data date) to complete the "Form footings" activity. Students can usually grasp this calculation easily, and are comfortable using percent complete $(\mathrm{P})$ as a good indicator of progress. However, the superintendent was never asked his estimate of the remaining duration needed to complete the "form footings" activity on the jobsite. Is it, in fact, six days, as calculated by the above equation? In many cases the answer will be no. It's entirely possible that "form footings" is, indeed, $40 \%$ complete, but the superintendent might feel that, say, nine (9) additional days are needed to complete the activity. 
Therefore, using percent complete $(\mathrm{P})$ as the only reliable indicator of an activity's progress can be misleading, and can lead to significant errors when performing an update. Students are often not aware of the problems that can be sewn into a schedule by relying solely on this approach for updating activities. What students rarely appreciate, and what is often missing in textbooks dealing with CPM scheduling, is the fact that original durations $\left(\mathrm{D}_{\mathrm{O}}\right)$ are often incorrect. On reflection, this makes perfect sense. When the CPM schedule is originally developed, the original durations $\left(\mathrm{D}_{\mathrm{o}}\right)$ for activities are, at best, educated guesses. It is difficult, if not impossible, for a scheduler to forecast the exact length of time an activity will require (e.g. 'form footings) weeks or months in advance of performing the actual work. As work progresses on the jobsite, superintendents and project managers will discover that many of the first estimates for activities' original durations will be flat-out wrong. If the error isn't corrected at the time of the schedule update, and the student is performing the update using percent complete $(\mathrm{P})$ as the only input, the calculated result for remaining duration $\left(\mathrm{D}_{\mathrm{R}}\right)$ will be incorrect. This error will cascade its way through the CPM via the relationships (logic ties) between activities, and produce an updated schedule that is inaccurate in its prediction of job completion.

Two separate tactics can be used to address this problem, and students should be made aware of both. The first approach is to change the activity's original duration $\left(\mathrm{D}_{0}\right)$ at the time of the schedule update. Let's assume in the example above that the superintendent agrees that 'form footings' is $40 \%$ complete, but also states that he thinks 9 days (from the data date) will be required to complete the work. Using the formula, we can reevaluate our estimate for the original duration, $\mathrm{D}_{\mathrm{O}}$ :

$$
\begin{gathered}
\mathrm{D}_{\mathrm{R}}=\mathrm{D}_{\mathrm{O}}(1-\mathrm{P}) \\
9=\mathrm{D}_{\mathrm{O}}(1-0.4) \\
\text { Solving for } \mathrm{D}_{\mathrm{O}} \text { yields } \mathrm{D}_{\mathrm{O}}=15
\end{gathered}
$$

We see then that the original duration $\left(D_{O}\right)$ must be changed to 15 days if the $40 \%$ complete (P) and 9 day remaining $\left(\mathrm{D}_{\mathrm{R}}\right)$ are used in the formula. The initial guess (made, perhaps, months ago) for $\mathrm{D}_{\mathrm{O}}=10$ days was wrong. Changing $\mathrm{D}_{\mathrm{O}}$ will produce an accurate depiction of the activity's progress. Students can easily learn and use this approach. However, owners may not be receptive to receiving updated CPM schedules in which the original duration $\left(D_{O}\right)$ for activities have been altered. Many owners use the originally-submitted CPM schedule as a baseline or target schedule against which future updates are compared. Changing original durations $\left(\mathrm{D}_{\mathrm{O}}\right)$ during a schedule update can raise an owner's eyebrows; he/she is usually interested in comparing the contractor's actual progress versus the planned progress. Changing original (planned) durations for activities may be unacceptable to owners once the original CPM schedule has been submitted and reviewed.

A second tactic for addressing the percent complete $(P)$ vs. remaining duration $\left(D_{R}\right)$ problem is to disable the formula within the scheduling software application. As mentioned, the formula is enabled by default in Primavera Project Planner version 3.1, (a popular software application package used to create and update CPM schedules). But the formula can easily be disabled by the software user. Once disabled, the link between percent complete $(\mathrm{P})$ and 
remaining duration $\left(D_{R}\right)$ is broken. If the formula is disabled, students must recognize that when they update an activity in the schedule, they must provide values for both percent complete $(\mathrm{P})$ and remaining duration $\left(\mathrm{D}_{\mathrm{R}}\right)$. When the formula is disabled, the data value for one variable (say, $\mathrm{P}=40 \%$ ) will not result in an automatic calculation for the other (remaining duration, $\mathrm{D}_{\mathrm{R}}$ ). Since "remaining duration always governs calculation of the schedule and determines finish dates for the activity", it's crucial that the scheduler input remaining duration $\left(D_{R}\right)$ for each affected activity during a schedule update. At their option, students can also input percent complete (P) for the activity, but P's value won't affect any schedule calculations done by the software.

Our students are encouraged to use this approach (disabling the formula) for several reasons:

a) Superintendents often have a better "feel" for the remaining duration $\left(D_{R}\right)$ of an activity as opposed to its percent complete (P). As such, the updated CPM schedule will be more accurate.

b) As shown in the previous example, enabling the formula and inputting percent complete $(P)$ will produce incorrect results for remaining duration $\left(D_{R}\right)$ if the initial guess for original duration $\left(\mathrm{D}_{\mathrm{O}}\right)$ was wrong, as is often the case.

c) As mentioned, owners often frown on the practice of altering activities' original durations $\left(\mathrm{D}_{\mathrm{O}}\right)$ when updated CPM schedules are presented to them.

A numerical example, taken from an exam given to our students, is below. In each case, percent complete is $20 \%$. However, as shown in the example, different completion dates can result depending on whether the formula is enabled or not. 
Consider the activities below:

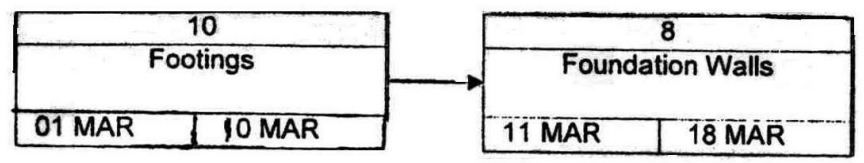

Legend

The Primavera software allows you the choice of linking remaining duration and percent complete. If remaining duration and percent complete are linked, the software uses this formula:

$\mathrm{D}_{\mathrm{R}}=\mathrm{D}_{\mathrm{O}}(1-\mathrm{P})$ where:

$\mathrm{D}_{\mathrm{R}}$ is the remaining duration

$\mathrm{D}_{\mathrm{O}}$ is the original duration

$\mathrm{P}$ is percent complete, expressed as a decimal.

a) Assume the following:

$\mathrm{X}$ Today is March 5.

$\mathrm{X}$ Remaining duration and \% complete are linked.

$X$ Footings are 20\% complete as of 5:00 p.m. today.

$\mathrm{X} 7$ day work week, no holidays.

Determine the completion date for foundation walls.

\section{Answer:}

$D_{R}=D_{0}(1-P)$

$D_{R}=10(1-0.2)$

$D_{R}=8$ days

\section{Footings: March $5+8$ days $=$ March 21}

b) Now, assume the following:

$\mathrm{X}$ Today is March 5.

$\mathrm{X}$ Remaining duration and \% complete are not linked.

$\mathrm{X}$ Footings are $20 \%$ complete, but remaining duration is estimated to be 9 days (as of 5:00 p.m. today)

X 7 day work week, no holidays.

Determine the completion date for foundation walls.

Answer:

$D_{R}=9$ days

Footings: March $5+9$ days $=$ March 14

Foundation Walls: March $14+8$ days $=$ March 22 
4) Options during schedule calculations: 'Retained Logic' vs. 'Progress Override':

The scheduler can adjust settings that affect how the software will perform calculations during the update. One option that students should be made aware of is the "progress override vs. retained logic" option. ${ }^{1}$ This option gives the student choices in how to handle out-of-sequence activities at the time of the update. An example of out-of-sequence activities might include the following:

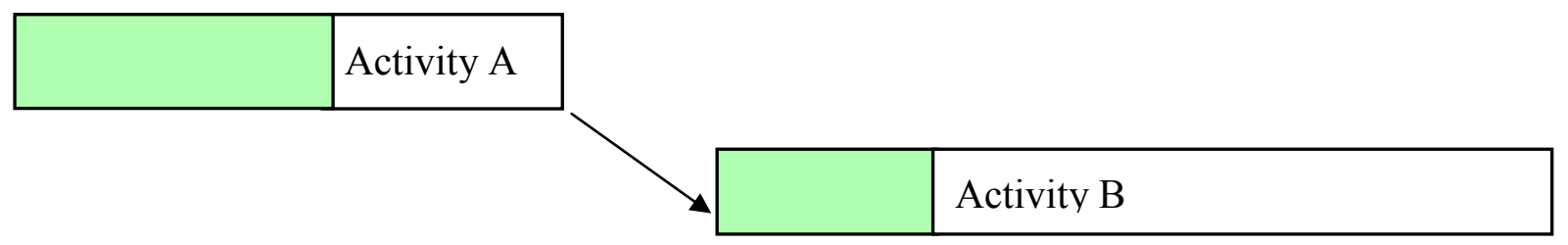

The arrow defines the relationship between activities A and B. The software uses relationship information in its calculation of start and completion dates for each activity. In this case, " $\mathrm{B}$ " is a successor to " $\mathrm{A}$ ". That means that " $\mathrm{B}$ " shouldn't begin until " $\mathrm{A}$ ' is $100 \%$ finished. However, the shaded area tells us some work has actually progressed on "B", even though the logic (relationship) dictates that "A" should be $100 \%$ complete prior to "B's" start. If the student chooses to schedule using 'retained logic', the software doesn't schedule the remaining duration of " $\mathrm{B}$ " until " $\mathrm{A}$ " is $100 \%$ complete. ${ }^{1}$ For example, assume the superintendent reports that " $\mathrm{B}$ " has indeed started, and has a remaining duration ("Rem Dur" in the graphic below) of 5 days as of the Jan. 4 data date (vertical blue line in graphic below). The resulting update would appear as below:

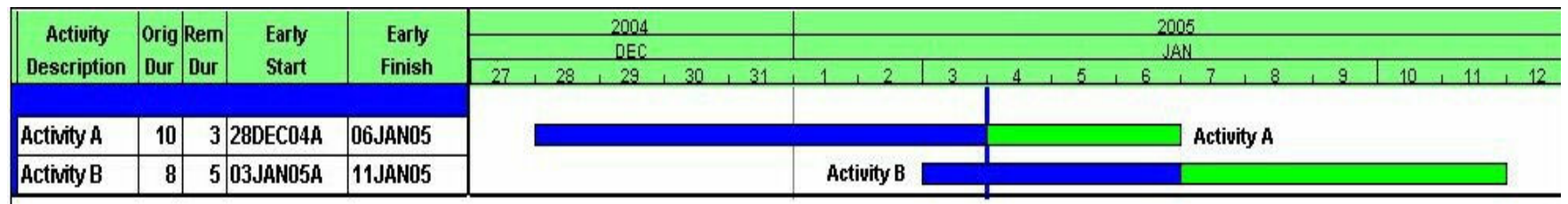

Notice, however, that the remaining duration of 5 days begins after " $\mathrm{A}$ " is $100 \%$ complete, $n o t$ at the data date (vertical blue line). This opens the door for confusion and miscommunication; the software setting ("retained logic') mandates that the " $\mathrm{A}$ " be complete before it schedules remaining duration for " $\mathrm{B}$ ". This is the default setting for the Privavera software, and it's crucial that students are aware of this. The superintendent has told the scheduler that "B" has 5 days of remaining duration as of the Jan. 4 data date. It's unlikely that the superintendent is aware of the details of how the software performs calculations; he simply reported that as of today, Jan. 4, "B" has 5 days more work before it's complete. As such, students must be made aware of this potential problem. Toggling the software setting from "Retained Logic" to "Progress Override" can produce updates that are more accurate. When the student chooses "progress override" the Primavera software "ignores network logic and allows the activity to progress without delay." 
Let's examine the above scenario using the "progress override" setting: The resulting update would appear as:

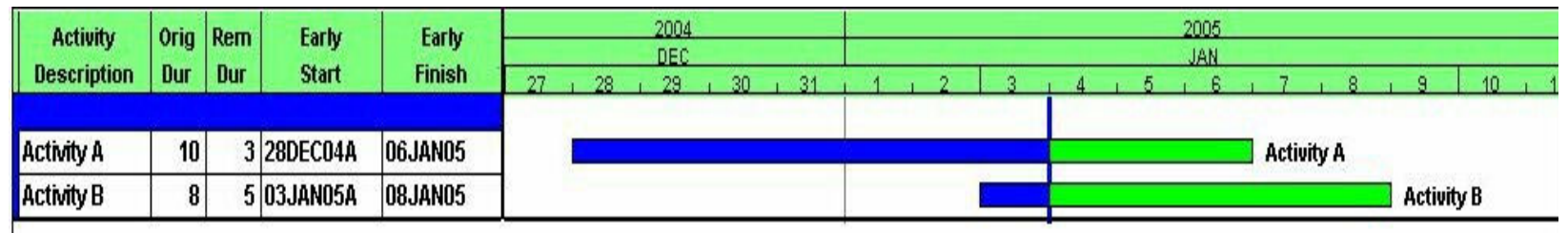

Note now that "B" has a finish date of Jan 8, instead of Jan 11. Note, too, that the superintendent's estimate of five remaining day duration for " $\mathrm{B}$ " is accurately reflected in the update. Some writers have argued that using the 'progress override' setting means, by definition, that "the schedule model is invalid." Nevertheless, the goal we stress to our students is to produce an accurate update of the CPM. Using the 'retained logic' setting does, indeed, preserve the logic and sequencing originally envisioned by the scheduler when the CPM schedule was developed. But few, if any, projects unfold exactly as originally planned; to cling to the original logic at the price of an accurate update is, in our opinion, ill advised. Students need to understand that the original CPM is a model only. Producing an accurate, usable CPM schedule update requires that the scheduler evaluate current conditions on the job, and use this information as a basis for forecasting the time frames for the project's outstanding activities.

5) Revision of network logic and lags between activities:

Even if 'progress override' is switched on, the student updating CPM schedules can still run into problems if network logic (relationship between activities) conflicts with actual progress on the job. Many CPM schedulers frown on the practice of revising network logic at any point during the job's progress. ${ }^{2}$ However, as the following example will show, results can be confusing if some logic isn't examined and revised during an update. Consider two activities tied via a 'finish to finish' relationship. This logic dictates that activity " $B$ " can't finish until "A" is completed:

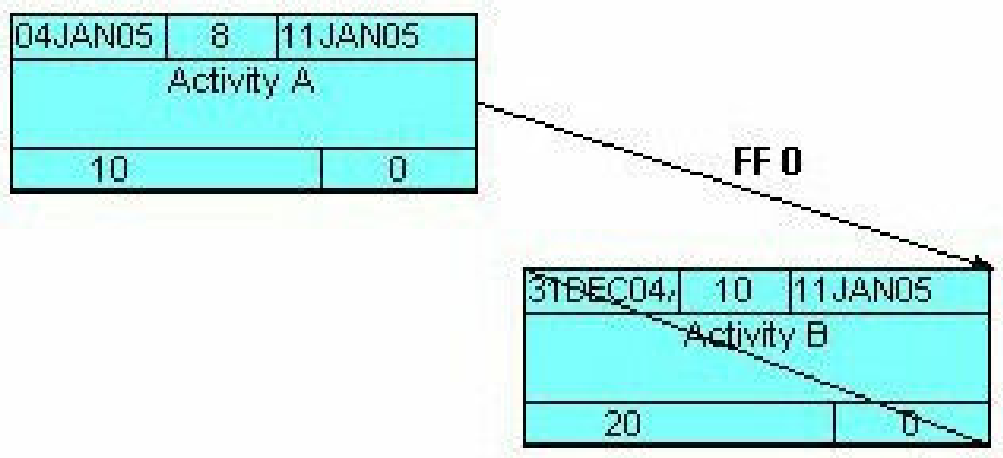

The diagonal slash through " $\mathrm{B}$ " indicates that work on " $\mathrm{B}$ " has started, but isn't yet complete.

"Proceedings of the 2005 American Society for Engineering Education Annual Conference \& Exposition Copyright@2005,American Societyfor Engineering Education” 
Let's assume the superintendent reports that "B" started on 31Dec. and has six (6) days remaining duration as of the Jan. 4 data date. Even with 'progress override' switched on, the resulting bar chart will appear as follows:

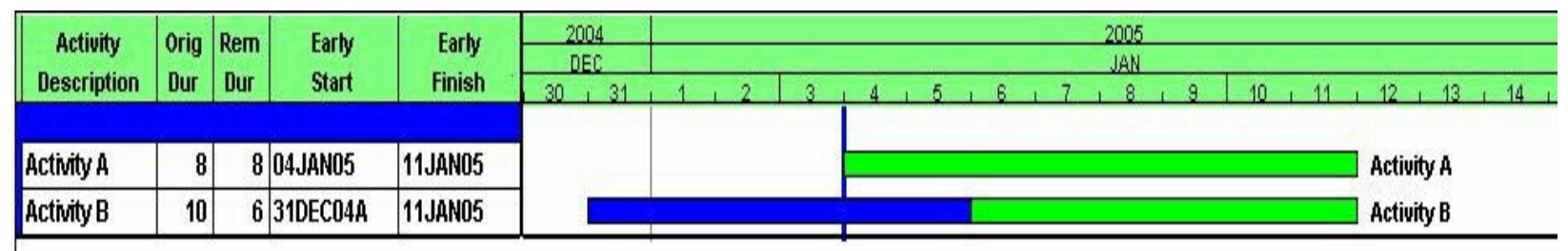

Today is Jan. 4 and the superintendent said "B" needs six more days to finish. Thus, we'd expect " $B$ " to finish on Jan $4+6$ days = Jan. 10. However, note above that the finish-tofinish constraint prohibits the completion of ' $\mathrm{B}$ ' until " $\mathrm{A}$ " is done. This means that the software requires that " $\mathrm{B}$ " have eight days of remaining duration (from the Jan 4 data date) instead of the six days reported by the superintendent. Again, the logic contained in the original model has overruled the reports from the field. This problem presents itself clearly in the bar chart above because the blue progress indicator on activity " $\mathrm{B}$ " has extended beyond the Jan. 4 data date. Students should address this problem by breaking (removing) the finish-to-finish logic tie between the two activities. Common sense dictates that current field conditions (the superintendent's estimate that " $\mathrm{B}$ " needs six days to finish) should trump the logic tie that was envisioned when the CPM was developed (perhaps months ago). As of today, (the Jan. 4 data date), the logic tie is now moot. If the tie is broken, the resulting bar chart would appear as follows:

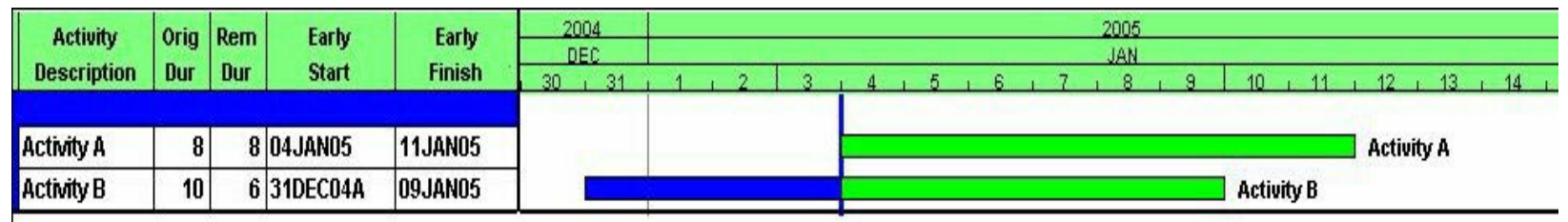

This bar chart is a much better reflection of current conditions in the field. Moreover, its appearance is more believable; the blue progress bar for " $\mathrm{B}$ " doesn't extend beyond the Jan. 4 data date. 


\section{Summary:}

Students and practitioners are often called on to update existing CPM construction schedules using popular application software. While many of the applications are easy to use, care must be taken to ensure an accurate schedule update. Students should examine each and every activity in the schedule that could have been affected since the last update, and they must be aware of the details of the software settings that can affect calculates times for downstream activities. Students should re-examine network logic and activity durations at the time of the update and change them (if project specifications allow) if necessary to better reflect the reality of progress on the job.

\section{References:}

1) Primavera Systems, Inc., Primavara Project Planner, version. 3.1 Reference Manual (included with software)

2) Korman, Richard, “Critics can’t find the Logic in Many of Today’s CPM Schedules," Engineering News Record Cover Story, May 26, 2003.

3) Zack, Jack G., “Construction Scheduling Games and Ways to Win,” Paper presented at the Primavera Users' Group, Los Angeles, 1995.

4) Associated General Contractors of America, Construction Planning \& Scheduling, 1994.

5) McDonald, Donald F., "Tripping Hazards in Schedules," Presentation given at the 2002 annual meeting of the American Association of Cost Engineers, Portland, OR. 2002.

\section{Biographical Information:}

Todd Dunn, P.E., is an Associate Professor in the Civil Engineering Technology program at the Rochester Institute of Technology. Prior to beginning his teaching career in 1992, he worked for three commercial construction contractors spanning eleven years. He worked in Asia for $2 \frac{1}{2}$ years on highway projects. He has extensive experience with CPM scheduling, and continues to consult. 